\title{
FICCIONES DE INMUNIDAD EN EL CINE CONTEMPORÁNEO EUROPEO. DOS LECTURAS DE LOS MARCOS SOCIALES DE LA INMIGRACIÓN DESDE WELCOME Y LE HAVRE
}

\section{Immunitarian fictions in contemporary European film: A reading of immigration social frames through Welcome and Le Havre}

\author{
María Pilar Rodríguez Pérez*; Fernando Bayón Martín** \\ * Universidad de Deusto \\ maria.pilar@deusto.es; fernandobayon@deusto.es
}

\section{Palabras clave \\ Inmigración \\ Inmunización \\ Alteridad \\ Frontera \\ Cine europeo}

\section{Keywords}

Immigration

Immunization

Otherness

Borders

European cinema

\begin{abstract}
Resumen
El discurso político oficial europeo se orienta cada vez más hacia una identificación de la inmigración y la llegada de refugiados con la amenaza y la necesidad de inmunizar a la comunidad frente a peligros tales como el terrorismo, la pérdida de capacidad económica o el riesgo de contagio de actitudes, valores y creencias. A través de la exploración de las películas Welcome de Philippe Lioret (Francia, 2009) y Le Havre de Aki Kaurismäki (Finlandia-Francia-Alemania, 2011), se propone una forma de actuación por parte de los protagonistas que, a riesgo de perder la inmunidad, buscan instancias que eviten ser solidarias con el poder, aunque sin poder actuar fuera del mismo. Este artículo ofrece un análisis desde la teoría fílmica y filosófica desde una perspectiva ética que persigue reformular conceptos ligados a la identidad europea. En estas películas, los ciudadanos europeos se ven expuestos al castigo resultante de incumplir las leyes por prestar apoyo y hospitalidad a inmigrantes o refugiados en situaciones de peligro. Estas dos películas son una muestra de un tipo de cine europeo en el que se proyectan historias con el potencial para propagar el contagio del acercamiento al Otro a través de una serie de encuentros en los que el afecto se impone sobre el miedo.
\end{abstract}

\section{Abstract}

Official European political discourse increasingly identifies immigration and the arrival of refugees with threat and the need to immunize the community against dangers such as terrorism, loss of economic capacity or risk of contagion of attitudes, values and beliefs. Through the exploration of the films Welcome by Philippe Lioret (France, 2009) and Le Havre by Aki Kaurismäki (FinlandFrance-Germany, 2011), a way of acting is suggested by the protagonists who, at the risk of losing immunity, seek instances that avoid forms of solidarity with power. This article offers an analysis based on filmic and philosophical theory from an ethical perspective that seeks to reformulate concepts linked to European identity. In these films, European citizens are exposed to punishment resulting from breaching the laws for providing support and hospitality to immigrants or refugees in situations of danger. These two films are representative of a type of European cinema which projects stories with the potential to spread the contagion of the closeness to the Other through a series of encounters in which affection wins over fear.

Rodríguez Pérez, Mạ. P. y Bayón Martín, F. (2018). Ficciones de inmunidad en el cine contemporáneo europeo. Dos lecturas de los marcos sociales de la inmigración desde Welcome y Le Havre. Papeles del CEIC. International Journal on Collective Identity Research, vol. 2018/1, papel 187, CEIC (Centro de Estudios sobre la Identidad Colectiva), UPV/EHU Press, http://dx.doi.org/10.1387/pceic.17673 


\section{INMUNIZACIÓN Y ALTERIDAD}

La inmunización se ha convertido en una categoría interpretativa que incide transversalmente en multitud de lenguajes particulares tales como la medicina, la política social o las tecnologías de la comunicación para hacer referencia a un mismo horizonte de sentido: el de asegurar el dominio de lo propio sobre toda expresión amenazadora de alteridad. En Immunitas. Protección y negación de la vida, el historiador napolitano de las doctrinas políticas Roberto Esposito (2005), comienza abriendo imaginariamente la página de un periódico actual para preguntarse: ¿qué tienen en común fenómenos como la lucha contra un nuevo brote epidémico, la oposición a la solicitud de extradición de un jefe de estado extranjero acusado de violaciones a los derechos humanos, el refuerzo de las barreras contra la inmigración clandestina y las estrategias para neutralizar el último virus informático? Entre los pensadores contemporáneos, Esposito se cuenta precisamente entre quienes más insisten en la "inmunización" como categoría hermenéutica a la que poder remitir los fenómenos citados. Bajo el perfil característico de cada uno de ellos descubre una analogía de fondo: cualquiera de estos acontecimientos puede ser entendido como una respuesta de protección ante un peligro:

"Ya se trate de la explosión de una nueva enfermedad
infecciosa, de la impugnación de prerrogativas jurídicas
consolidadas, de la repentina intensificación del flujo
migratorio o de las maniobras sobre los grandes sistemas de
comunicación - por no hablar de un ataque terrorista-, lo
que se presenta es, no obstante, la ruptura de un equilibrio
anterior y, por ende, la exigencia de su restitución" (Esposito,
2005: 9).

La inmunización es una categoria interpretativa que se apoya en la idea de un peligro indeterminado que, en todo caso, se presenta con los rasgos de la intrusión. Ese peligro es susceptible de configurarse de manera específica, de individualizarse o resituarse: ya sea el asediado el cuerpo de un individuo (por una enfermedad infecciosa); el cuerpo político (por una injerencia violenta o intromisión terrorista); o el cuerpo electrónico (por parte de un mensaje aberrante), lo que permanece invariado - dice Esposito- "es el lugar en el cual se sitúa la amenaza, que es siempre el de la frontera entre el interior y el exterior, lo propio y lo extraño, lo individual y lo común. Alguien o algo penetra en un cuerpo 
-individual o colectivo-y lo altera, lo transforma, lo corrompe" (2005: 9).

Este artículo estudia cuál es la retórica audiovisual que mejor se presta a representar esta mecánica disolutiva, ya que términos como contagio, contaminación o amenaza la sostienen. Tal justificación de la necesidad de reforzar los procedimientos inmunitarios se ve agravada por la elevación de los virus a condición de alegoría social. Es necesario aprender a rechazar que lo que ocurre en Brindisi, Lampedusa o Melilla pueda ser referido mediante esa alegoría informativa que hace de la inmigración una suerte de matriz viral. Estas entidades biológicas carentes de autonomía metabólica tienen la capacidad de autoreplicarse utilizando una maquinaria celular ajena; inertes de por sí, activan su ciclo reproductivo sólo tras abrir una brecha en la membrana de una célula de cuya hospitalidad metabólica dependen para poder copiar su material genético. El relato vírico sirve hoy para alegorizar mil y una aventuras de la política. Y lo que el relato ensambla es una entidad tóxica externa con una capacidad incontrolable para multiplicarse a sí misma, que sólo se activa desde el interior de un metabolismo que hace el papel simultáneamente de huésped químico y de víctima invadida. Lo que era sano, seguro e idéntico a sí, ahora parece expuesto a una contaminación, corriendo el riesgo de degeneración, pero hay que recordar que es su propio metabolismo lo que ha ayudado a que la toxina se copie. Esta retórica biológica formula y alienta todo un catálogo de miedos.

El cine -especialmente en géneros como el terror, el western y la ciencia ficción - ha ayudado a sacar a la luz algunas contradicciones del paradigma inmunitario, esas que el mismo Esposito aprovecha a fondo pues, como buen "dialéctico", dista de temerlas y sabe que las contradicciones alargan la vida de aquello que las soporta. La imagen cinematográfica llega más allá, hasta el punto de plantear si la vida social no se desarrolla en un horizonte radicalmente ajeno al definido por el exitoso paradigma de la inmunización, pues conoce modos de conservación muy distintos a los de la mera protección negativa. Esposito nos recuerda, como lo hacen Agamben (1999), Rancière (2006), Blanchot (2002) y Nancy (2015), que nacimos como hijos de un silencio inmunitario. Fuimos, como embriones, un elemento extraño al que la lógica inmunitaria del cuerpo materno olvidó atacar. La noción se asemeja a la del extranjero elegido al que se le permitió prosperar en 
otra tierra porque no venía de ninguna tierra precedente. Todos fuimos alguien cuya única alter/nativa consistió en salir hacia otra parte.

La retórica que habla de la sociedad como si hablara de un organismo autoprotegido (Tauber, 1994) ha sido producida igual que un remake, a veces pésimo, de la investigación inmunológica en los sectores de la medicina y la bioquímica. En el horizonte del biopoder, uno de los brazos ejecutores de la filosofía del capitalismo avanzado, los ámbitos de la política, el derecho y la economía dependen del bienestar cualitativo y del incremento cuantitativo de la población considerada en su aspecto estrictamente biológico. La vida, según Esposito, se hace en todos los sentidos asunto de gobierno, así como éste deviene antes que nada gobierno de la vida. La última metamorfosis de la dialéctica inmunitaria nos coloca muy lejos de aquellos esquemas donde la interacción de los antígenos y los anticuerpos tenía lugar en el marco fronterizo bien delimitado de un interior y un exterior de manera que la ciencia podía emplearse en una topología del enemigo de ese domus (y ese demos) que es el cuerpo. Tal bipolaridad es hoy médicamente improcedente y socialmente improductiva. Los límites de un cuerpo - los límites de la sociedad, si acaso- no bloquean a éste en un mundo clausurado militarmente; "por el contrario constituyen el margen, delicado y problemático por cierto, pero siempre permeable, de su relación con aquello que, aunque se sitúe en su exterior, desde el comienzo lo atraviesa y lo altera" (Esposito, 2005: 241). Bauman incide en la deriva que ha ido tomando la idea de una "sociedad abierta" hacia el terror que impulsa el falso cobijo de lo inmunitario:
"Si la idea de una 'sociedad abierta' representó originalmente la determinación de una sociedad libre orgullosa de su apertura, hoy evoca en la mayoría de las mentes la experiencia aterradora de unas poblaciones heterónomas y vulnerables, abrumadas por fuerzas que no pueden controlar ni comprender plenamente, horrorizadas ante su propia indefensión y obsesionadas con la seguridad de sus fronteras y de la población que reside en el interior de éstas, dado que es precisamente esa seguridad fronteriza e intrafronteriza la que escapa a su control y parece estar destinada a quedar fuera de su alcance para siempre" (2007: 125-126).

¿Cómo pensar el cruzamiento de lo inmune y lo común si la frontera de los cuerpos se ha vuelto indecidible; si las antinomias entre la interioridad y la exterioridad se han vuelto no dialectizables? (Derrida, 
2005; 2006). Desde el acercamiento de Esposito, las respectivas relaciones de la comunidad y la inmunidad con la raíz latina - munus, en su triple acepción de obligación (onus), función (officium) y don (donum)-, confrontan a ambos términos con una forma del deber, como negación o protección de la vida. Si evaluamos cuál es hoy la retórica más cohesionadora de nuestras democracias mass-mediáticas, se advierte que el tropo inmunitario de autoprotección ha tomado la delantera a las viejas figuras de lo comunitario: si transformamos discursivamente cualquier proceso social en algo de lo que debemos protegernos seguramente recabaremos más adhesiones que si pretendemos hacerlo pasar por una obligación colectiva. A cambio, la deriva de las políticas inmunitarias tiene un carácter paradójico, a veces rayano en la tragedia: el sistema inmune acaba en infinidad de ocasiones atacando a la totalidad que supuestamente habría de defender, viniendo a causar a la postre el mismo caudal de riesgo y muerte que pretendía conjurar. Bastaría recordar, como hace Esposito (2005), el caso del asalto en 2002 de las fuerzas militares rusas al Teatro Dubrovka de Moscú, en que un comando checheno retenía a centenares de personas, y que concluyó con la muerte de 130 rehenes tras la intervención de los rescatadores.

\subsection{Migraciones y afiliaciones identitarias}

Entre otros investigadores, Appadurai (1996) insistió al final del siglo XX en uno de los temas aún de más circulación en nuestros días: cómo el tratamiento de las migraciones por parte de los medios de comunicación han modificado profundamente los imaginarios públicos y privados, transformando radicalmente los horizontes potenciales de esa institución que tanto sedujo a los lenguajes de la democracia moderna, la identidad. La experiencia del emigrante pone en crisis cualquier profilaxis doméstica o domesticadora. El emigrante usualmente permanece fiel a una comunidad imaginada; pero, al mismo tiempo, se ve obligado a transformar su imaginación cultural, sus tradiciones, su lengua, sus ritos religiosos, en un espacio traducido. EI concepto del "otro" en la imagen cinematográfica se ha deslizado en ocasiones hacia una poética de la alteridad en exceso lastrada por el esencialismo. Esposito decía con mucha precisión que la comunidad es irreductible al "lugar común" (2006b: 317). 
El extranjero constituye un momento estructural de esa mise-en-escène del domus, que no puede sobre-vivir sin imaginarse las más radicales amenazas y peligros: el otro es una construcción inevitable dentro de nuestras políticas de auto-reconocimiento. Quizás no hay mejor forma de alentar y justificar la defensa de un entorno identitario que fabricar la conciencia de que éste se ha vuelto extremadamente vulnerable. El "otro" es así un agente imprescindible dentro de cualquier lógica política de autodeterminación, para la cual la vulnerabilidad es más una razón de ser que un riesgo verdadero. Como apunta Bauman, los Estados se ven incapaces de cumplir la promesa de proteger a sus súbditos, y han trasladado "el énfasis en de la protección desde los peligros para la seguridad social hacia los peligros para la seguridad personal" (2007: 13).

Para comprender mejor los peligros de esta política, resulta útil volver a entrar en "La farmacia de Platón", donde Derrida desarrolla la doble etimología griega de Fármacon - curativo o veneno- y de Fármacos el brujo, el envenenador, el forajido a quien se inmola en expiación de las faltas de una ciudad- (2007). El fármacos, recordemos, era aquel con cuya muerte, o cuya exclusión allende el fuero interno de la ciudad, se pretendía neutralizar una calamidad. Él no era la calamidad misma, sino alguien que la representaba. Alguien escogido desde dentro de la comunidad sufriente $-y$ toda comunidad tienen un reservorio de rechazados ad hoc-; pero que encarnaba la alteridad del mal, para que su sacrificio obrara la victoria sobre aquello otro - peste, hambre o cólera divina- que venía a afectar imprevisiblemente al interior.

La ceremonia del fármacos ateniense ayuda a imaginar las operaciones a que conduce la decisión de interpretar al extranjero como "otro", a quien nos repugna por principio reconocerle el fuero de la segunda persona. Pero esa decisión - de que permanezca siendo él y no salte al tú- no podrá jamás organizarse de acuerdo a las funciones habituales de la política, a saber, marcar un límite entre un interior digno de amparo y protección y un exterior hecho de aquello ante lo que nos queremos inmunizar. No es posible puesto que esa compulsión territorializadora de lo político se ha reblandecido; ya no hay un "nosotros" para el que trabaja en exclusiva lo político. Ese nosotros no es jamás la multiplicación de lo mismo e idéntico. Las fronteras del Estado consienten diariamente en un martirio por cuerpos interpuestos: los cuerpos de ellos. Tal categoría pronominal se aplica por igual a los terroristas o a los inmigrantes, ellos, los que no podemos traer ante 
nuestra presencia inmediata, ellos: la tercera persona de la forma verbal que, recurriendo a Benveniste (2007) y a Esposito (2009), tiene precisamente por función expresar la no-persona, e impide establecer una correlación de personalidad como la del yo frente a un tú, ya que el hablante toma por sujeto de referencia a ese plural sustraído a la esfera personal del tú, que es exactamente la no-persona carente de unicidad (los rumanos, los marroquíes, los subsaharianos, los gitanos... ellos) e irreversibilidad ( ¿a que ellos no pueden cambiarse por ti?).

Volvamos a esa inquietante pregunta, que liquida la habitual lógica Intra- / Extra muros de lo político: ¿quién hace las veces de fármacos? ¿Quién el chivo expiatorio? ¿Quién encarna la catástrofe e introyecta la amenaza, estando su cuerpo y su vida comprometidos sin embargo con el derecho a pertenecernos? ¿Quién representa la alteridad del mal sin ser ni otro ni malo? Entre algunos otros casi igual de terciados, impersonales e irreversibles, el inmigrante ilegalizado.

\subsection{Frontera, ilegalidad y temor}

Sólo podrá surgir una respuesta más adecuada y sostenida a la cuestión de las migraciones si se considera el espacio que nombran esos desplazamientos. La llegada de inmigrantes y refugiados evoca, ante todo, un límite capaz de reinterpretar la naturaleza misma del espacio interior. Una frontera es una economía del reconocimiento. Como toda economía no puede crecer sin un montante organizado de exclusiones, sin un régimen controlado de pérdidas. En la actualidad, junto a unas fronteras físicas que son tan localizadas, proliferantes y mortales como de costumbre, existe un complejo proceso de metaforización en torno a la frontera que tiende a hacer de ella una entidad sutil y virtual que ya no tiene nada que ver con los marcadores de suelo. El border-thinking es el fetiche de un lenguaje que arrasa en los estudios culturales, y cuya visión del mundo está fabricada de junturas múltiples y redes sinápticas, de descolonizaciones del ser y del pensar, de una profilaxis política diferente a la del Imperio (Spivak, 1999). Mientras la frontera metafórica ha sido elegida por la filosofía de la cultura como la viva imagen de la complejidad en que tanto nos apetece reconocernos, las fronteras físicas siguen ejerciendo, en una medida crecientemente alarmante, de cadalso preventivo de los Estados.

La frontera es el espacio en que se resuelven las cuestiones de deviance: la percepción social de los indocumentados se construye en la frontera, 
exterior e interior, y culmina en discriminación y sujeción al control organizado por parte del Estado. Las fronteras son, entre otras cosas, espacios retóricos desde los cuales se comienza a legitimar socialmente la discriminación política del indocumentado. El cine contribuye a construir y deconstruir esas retóricas. Porque, ¿cuál es el efecto de una frontera interior? Consiste en la generación de espacios sociales de noexistencia, marcos de invisibilidad diseñados para que la contradicción más básica entre la presencia física del inmigrante indocumentado y la negación oficial de que es objeto no suponga en modo alguno un escándalo social. ¿Cuál es el espacio de la ilegalidad? Un campo de visibilidad invisible, de estar sin estar, de exclusión en movimiento, de creencia en que la realidad es el orden de todo aquello que puede ser documentado. Tal situación da pie a soluciones de carácter paradójico tales como que en muchos sitios la estancia no autorizada se penalice con estancia forzosa (en la cárcel) o que se acceda al estatus legal por acumulación verificable de una residencia ilegal continuada.

Suena todavía desgraciadamente joven la advertencia foucaultiana acerca de que la existencia de una prohibición legal crea en torno suyo un campo de prácticas ilegales (1989). Por ello, urge sacar a la luz las violencias epistémicas que concurren en nuestras retóricas de la ilegalidad, pues ésta, tanto en sus teorías como en sus prácticas, es una relación social inseparable de los espacios en que se expresa y constituye la ciudadanía. Sería en vano pretender haber localizado comunidades de migrantes indocumentados herméticamente selladas. Pese a todos nuestros tics inmunitarios, la mal llamada vida cotidiana es un amasijo de intercambios, más o menos formales, entre indocumentados, regulares, nacionales y demás formaciones retóricas. $\mathrm{El}$ cine ha penetrado de diversas formas en este amasijo de inter/cambios.

Podría valer para los filmes que a continuación se analizan las palabras que Jacques Rancière dedicara a la obra del cineasta portugués Pedro Costa:

"El cine no puede ser el equivalente de la carta de amor o de la música de los pobres. Tampoco puede ser el arte que se limita a devolver a los humildes la riqueza sensible de su mundo. Debe aceptar no ser más que la superficie donde procura cifrarse en nuevas figuras la experiencia de quienes han sido relegados al margen de las circunstancias económicas y las trayectorias sociales. Es menester que esa superficie dé 
acogida a la escisión que separa el retrato y el cuadro, la crónica y la tragedia, la reciprocidad y la fisura. Un arte debe hacerse en lugar de otro" (Rancière, 2012: 141).

Un arte debe hacerse en lugar de otro; pero, ¿cuál es ese lugar en que nos pone el otro? La ficción cinematográfica ha sido muy sensible a las dos opciones más recurrentes a la hora de responder a esta pregunta. De un lado, la Europa Fortaleza se blinda como un club de circulación liberalizada para sus socios de mayor edad. Se trata de una reacción típicamente proteccionista de cara a un exterior identificado como un "ubi leones", igual que lo eran los extrarradios del imperio en los mapas de la antigua Roma. La presencia del otro, en tanto peligro, invasión o amenaza, lleva a reforzar el culto de lo mismo, a que el continente se enroque en su identidad "más" propia, aunque se trate tan solo de una ficción profiláctica. Sin embargo, Europa conoce mil pequeñas historias acerca de cómo los valores que creíamos constitutivos de nuestra identidad pueden quedar profundamente marcados por el contacto con el otro, transformados por la alteridad. Cierto cine europeo rescata con emoción cívica esa sensibilidad que, al contacto con el refugiado o el inmigrante, se atreve a poner en tela de juicio los valores asentados, dando lugar a formas de compromiso con el otro que progresan asumiendo riesgos políticos, incurriendo eventualmente en transgresiones legales y dando lugar a múltiples replanteamientos éticos. Frente a la "bunkerización" habitual -el otro como oportunidad para la autoafirmación más obtusa-, son muchos los casos en que ese otro tiene la capacidad de reformular, y hacer reformular, la existencia de muchos de los protagonistas de estas ficciones. El cine es hospitalario, gracias a esas ficciones, tanto con la fisura como con la reciprocidad.

\section{CINE EUROPEO: HACIA UNA BIOPOLÍTICA AFIRMATIVA}

Existe en los debates sobre la inmigración en Europa un ciclo perverso que comienza y termina con la muerte de los migrantes. Las etapas intermedias consisten en encarcelar y penalizar a los supervivientes, seguidas de un llamamiento a políticas más restrictivas y basadas en el control, aduciendo un enfoque de seguridad de la migración para proteger los derechos fundamentales de los ciudadanos de la UE. Como apunta Bauman (2007), en el mundo globalizado actual, el Estado ha perdido la capacidad de proteger a sus súbditos frente a las amenazas de la 
existencia; frente al temor de la amenaza terrorista o a otros peligros que se asocian a la inmigración, se desplaza "el énfasis de la "protección" desde los peligros para la seguridad social hacia los peligros para la seguridad personal" (ibídem: 13). En estas circunstancias, es necesario preguntarse cómo se puede reorientar la discusión sobre la inmigración y la difícil situación de los refugiados políticos en Europa para rescatar los discursos que se alejan de la necesidad de protección inmunitaria. ¿Quiénes son los agentes sociales que pueden aportar enfoques criticos para pensar sobre este tema de una manera diferente? ¿Puede proponer el cine europeo una representación no solidaria con el poder a través del contagio con formas de vida consideradas inferiores y amenazadas por la obsesión inmunitaria?

Varios Estados miembros de la UE han recurrido a medidas penales para disuadir a los inmigrantes de entrar o permanecer en su territorio de forma irregular (FRA, 2014); además, los Estados miembros de la UE pueden castigar a las personas que ayudan a los inmigrantes irregulares a entrar y permanecer en la UE (FRA, 2014: 1). El uso de sanciones penales y encarcelamiento para combatir la migración irregular afecta no sólo a los inmigrantes, sino que condiciona negativamente la manera en que las sociedades europeas los perciben. El endurecimiento del discurso político e institucional europeo y al auge de los partidos políticos de extrema derecha en varias naciones europeas no ocultan una propagación del miedo ante el contagio asociado a la llegada de los inmigrantes (la amenaza terrorista, el riesgo de retroceder en avances sociales, la pérdida de riqueza material de cada Estado, el aumento del desempleo o el acceso masivo a la educación o al sistema sanitario de los que llegan). Frente a este discurso, ciertos intelectuales y artistas europeos adoptan una voz discordante.

Ballesteros ha definido recientemente el cine europeo de la inmigración como categoría de estudio. Señala que sus directores desean crear una conciencia ideológica y artística acerca de las condiciones sociales de los inmigrantes en la Unión Europea, y sacudir a las audiencias de su silenciosa complicidad con asuntos ligados a leyes y patrones relativos a la inmigración (2015: 25). Estudia la fortificación de las fronteras físicas y la progresiva implantación de infraestructuras tecnológicas para autorizar medidas de control drásticas e inhumanas (2015: 177). El presente artículo, sin despreciar las aportaciones de Ballesteros y de los lúcidos y pertinentes resultados surgidos de la creciente investigación académica desplegada en torno a los fenómenos de la inmigración y de su representación fílmica, se 
afana en leer estas películas desde la perspectiva de la resistencia a la presión inmunitaria y analiza tanto las instancias en las que se trata de imponer esa obligación como las actuaciones que reivindican una bioética positiva. Para este análisis es fundamental recordar la distinción que lleva a cabo Esposito entre communitas e immunitas: "Si la communitas es aquello que liga a sus miembros en un empeño donativo del uno al otro, la immunitas, por el contrario, es aquello que libra de esta carga, que exonera de este peso" (2012: 104). Las dos películas trazan un desarrollo argumental que va de la indiferencia de los protagonistas (e incluso de la complicidad con el sistema ligado a la immunitas) hasta la prestación de ayuda al inmigrante o refugiado, poniendo en riesgo su inmunidad. Las dos películas seleccionadas para el presente artículo forman parte de un corpus amplio que, dentro de la cinematografía europea y ya desde los años setenta con películas tales como Angs essen Seele auf/Todos nos llamamos Ali (Fassbinder, 1974), hasta la actualidad, con una nueva aportación filmográfica de Kaurismäki con Toivon tuolla puolen (El otro lado de la esperanza, 2017), apuestan por volver la mirada hacia representantes de la emigración o de los refugiados desde una perspectiva reivindicativa de los valores humanistas defensores de la dignidad humana. Su selección responde a la oportunidad que ofrecen para el análisis desde perspectivas diferentes en cuanto a la selección de sus protagonistas, de su pertenencia a generaciones y a estamentos sociales alejados entre si y a estilos fílmicos diversos, pero con una intención similar en su reivindicación de alejamiento de la imposición inmunitaria. Ambas películas se apartan de una tendencia hacia la racialización o el victimismo, que en ocasiones ha marcado los intentos de acercar al público europeo desde una distancia ligada al sensacionalismo, y no mediante una implicación afectiva (Santaolla, 2010).

La capacidad de este tipo de cine europeo para afectar de modo efectivo a sus audiencias no es algo que deba darse por supuesto; hay que tener en cuenta el potencial de estas películas para promover un sentimiento de atracción y familiaridad o de rechazo en la audiencia en un proceso en el que la jerarquía y los términos de inclusión y exclusión son determinantes (Lykidis, 2009). Nociones tales como la identificación o el alejamiento de las premisas expuestas mediante la aceptación por parte de la audiencia de un cine que muestra el riesgo del contagio es fundamental en este contexto; las dos películas seleccionadas muestran un afán común para exponernos a una contemplación inquietante y transformadora. 


\subsection{Welcome}

La película Welcome, dirigida por Philippe Lioret, cuenta la historia de un joven iraquí-kurdo de 17 años llamado Bilal Kayani (Firat Ayverdi) que llega a Calais después de viajar a pie durante tres meses. Determinado a continuar su viaje y reunirse con su prometida Mina (Derya Ayverdi), cuya familia se trasladó a Londres, Bilal intenta pasar la frontera escondido dentro de un camión. Cuando el intento falla, Bilal es devuelto a Calais. Ante la imposibilidad de llegar a Inglaterra por medios legales o ilegales, comienza a tomar clases de natación con Simon Calmat (Vincent Lindon), un ex campeón e instructor de natación en la piscina local, ya que aspira a cruzar el Canal a nado. En su primer intento de cruzar el canal es rescatado cuando Simon llama a los guardias diciéndoles que Bilal es su hijo, pero la segunda vez muere. La película termina cuando Simon visita a Mina en Londres y ella le dice que se casará en diez días obligada por su padre, que ha concertado la boda.

La sociedad francesa ha experimentado un intenso debate político y emocional en torno a la legislación sobre inmigrantes, y específicamente, sobre la influencia de la xenofobia y el racismo en la política francesa. Como informa Emmons (1997), en marzo de 1997 la Ley Debré, que endurecía las medidas contra la inmigración, fue aprobada por el Parlamento francés. Durante los meses previos a su aprobación, miles de manifestantes salieron a las calles pidiendo su eliminación: "Actores, directores, artistas, escritores, músicos, científicos, abogados, alcaldes y jueces anunciaron que desobedecerian la Ley a riesgo de ir a la cárcel si la Ley era aprobada. Las traducciones son de los autores y se mantiene la cita en el idioma original en el texto." (ibídem: 359). Se percibe una división constante en Francia entre la legislación y el discurso institucional, por un lado, que tratan de forzar medidas inmunitarias para protegerse de la amenaza de los inmigrantes, y la respuesta de intelectuales y artistas por otro, que recuerdan la obligación de brindar hospitalidad desde una actitud más humana.

En el contexto del Proyecto Debré, Balibar publicó en Le Monde, el 19 de febrero de 1997, un artículo titulado "Estado de Emergencia Democrática", en el que expuso los valores - la hospitalidad, la verdad y la inviolabilidad de los seres humanos-que constituyen la base de toda comunidad en términos de justicia y derechos:

"Un poder es legítimo en la medida en que no entre en conflicto con ciertas leyes superiores de la humanidad (el 
respeto por los vivos y los muertos, la hospitalidad, la inviolabilidad del ser humano, las limitaciones de la verdad). Dichas leyes no escritas están por encima de cualquier legislación de circunstancia" (1997).

La película aborda directamente otra ley controvertida sobre la ayuda que los ciudadanos franceses pueden proporcionar a los inmigrantes. La decisión de Simon de ayudar a Bilal entra en conflicto con el artículo L622-1 del código penal francés, que considera un delito ayudar a los inmigrantes indocumentados. En virtud de esta legislación, cualquier persona declarada culpable de proporcionar "asistencia a la entrada, viaje o estancia indocumentada" a un inmigrante puede ser multada en 30.000 euros y encarcelada por un máximo de cinco años. Se llama el Código de Entrada y Residencia de Extranjeros y de Derecho de Asilo (CESEDA). Como informa Dahlberg, el artículo fue denominado popularmente "hospitalidad como delito penal" o "solidaridad como delito" (2013: 50), aludiendo a la naturaleza perversa y contraria a la humanidad del Código.

La transformación que experimenta Simon desde su inicial indiferencia hacia los inmigrantes hasta su compromiso con el joven Bilal, al que llega a acoger en su casa, es ejemplo de esa obligación de hospitalidad que la tradición intelectual francesa ha ensalzado por encima de la ley. La ayuda proporcionada por Simon en la película retrata una situación real en Calais, donde desde hace décadas los residentes locales nunca han dejado de proporcionar ayuda a los migrantes. Calais representa el espacio fronterizo por excelencia en los términos anteriormente reseñados; los continuos esfuerzos por parte de las autoridades francesas por desmantelar los campos de inmigrantes y refugiados en la zona (conocida como la jungla), chocan con la pertinaz determinación de quienes acuden alli de nuevo, empeñados en alcanzar la costa británica.

La marca de la otredad asociada a la inmigración como fenómeno infeccioso del que es necesario protegerse se exhibe en la película a través de ciertas prácticas inmunitarias desarrolladas por las autoridades. Calais constituye un ghetto marginal, donde se hace visible la separación del continuo vital entre esas formas de vida más o menos valiosas que señala Esposito (2006a). Al ser descubierto en su intento de pasar la frontera oculto en el camión, Bilal comparece delante del juez, quien señala que no puede ser repatriado dado que procede de un país 
en guerra, pero a la vez le hace saber que "la policía tiene órdenes de devolver a su país a personas como usted". Bilal queda en tierra de nadie, en el no-espacio que impide la integración y que refleja la marca de la immunitas como defensa de lo propio que interrumpe el circuito de donación recíproca en su afán de evitar el contagio comunitario. Los inmigrantes y refugiados son señalados con un número en la mano, marca indeleble que permite su inmediato reconocimiento y su falta de higiene constituye otra marca de su carácter infeccioso. Bilal logra a un tiempo mejorar su habilidad como nadador y mantener su higiene personal por medio de las visitas diarias a la piscina.

La noción de hospitalidad y su caracterización en Welcome han sido exploradas por autores como Dahlberg (2013) y Parvulescu (2014), entre otros. El título de la película coloca de inmediato a su público en un contexto en el que se sugiere una reflexión sobre el concepto de hospitalidad. El vecino de Simon representa al sector intolerante de la población que insiste en utilizar el lenguaje asociado con la legislación para rechazar los esfuerzos de Bilal para reunirse con su prometida y de Simon para ayudarlo. El vecino se refiere a Bilal como "ilegal" y acusa a Simon de "traer a extranjeros ilegales aqui". Irónicamente, el vecino tiene un felpudo con la inscripción Welcome; es interesante notar que tanto el título de la película como la inscripción en el felpudo son en inglés, como si esa expresión de hospitalidad sólo pudiera tener lugar en un idioma distinto del francés. Varios idiomas se hablan en la película (francés, inglés y kurdo) de acuerdo no sólo a las lenguas nativas de los personajes, sino también como resultado de la configuración espacial particular de esta zona de contacto/frontera. Simon y Bilal se comunican en inglés desde el principio, aunque no sea la lengua materna para ninguno de ellos; funciona como la herramienta en la que se puede establecer la comunicación y facilita el contrato inicial. Smith (2012) ha estudiado en detalle el uso de las lenguas en la película y define el uso del inglés por los protagonistas como un lenguaje "umbral", accesible a dos hablantes, como medio de establecer comunicación sin exigir asimilación: este lenguaje les proporciona un espacio compartido desde el que cada uno puede avanzar hacia el otro o retirarse al suyo propio. Este uso de la lengua inglesa ofrece una alternativa más efectiva para la comprensión mutua y se opone a las prácticas o intentos monolingüísticos de los gobiernos europeos de imponer una hegemonía lingüistica asimilativa como requisito para la integración. En contraste, 
la lengua francesa es utilizada a lo largo de la película por los representantes institucionales de una manera estrictamente monolingüística, y como señala Smith, con excepción de su personaje principal, la imagen de Lioret de la cultura de acogida es la de la agresión expresada a través del lenguaje como arma de exclusión privilegiada (ibídem: 87). Esta caracterización exclusiva de la lengua francesa en la película está estrictamente relacionada con la legislación inmunitaria, que penaliza a los ciudadanos locales por ayudar a los inmigrantes.

Dahlberg (2013) y Parvulescu (2014) aluden a la actitud hostil de la sociedad francesa, ejemplificada en la película por la policía, las autoridades locales y el vecino, que contrasta con la tradición hospitalaria. Derrida ha escrito extensamente sobre la noción de hospitalidad (2006) y aborda precisamente la contradicción expuesta en la película: la hospitalidad universal debe ser un derecho absoluto que en la práctica se vuelve contingente y restringido por las leyes particulares. El deseo de Simon de ayudar a Bilal nace de la compasión y de un instinto afectivo que le impulsa a ayudar a los que más necesitan la hospitalidad. Simon está siguiendo la ley de la hospitalidad universal y absoluta en lugar de ser limitado por las leyes particulares que la restringe. Simon ejemplifica la comunidad de exposición de la vida al contagio de la relación; rechaza la protección inmunitaria y se expone al castigo.

Como señala Esposito, no hay realidad fuera del poder, y la capacidad de acción se da por medio de prácticas que eviten ser solidarias con él (2006b). El trágico final de la película, en el que Bilal muere ahogado cuando trata de escapar de los guardacostas, evita un final feliz o esperanzador. Welcome recuerda que la deshumanización se está convirtiendo en un procedimiento común para los ciudadanos europeos en las zonas fronterizas. Expone la crueldad del sistema económico a nivel global y de los discursos y prácticas políticas e institucionales en una Fortaleza Europa cada vez más inclinada a imponer condiciones drásticas y a fortificar aún más sus fronteras. El hecho de que la película ofrezca un final caracterizado por la desesperanza en la que los inmigrantes tienen muy poca o ninguna capacidad de actuación debería situarse en un contexto europeo marcado por la falta de hospitalidad hacia los inoportunos recién llegados y por una legislación dura que afecta tanto a los ciudadanos europeos como a los inmigrantes. La película muestra la transformación del protagonista cuando se ve 
afectado por la individualidad del "Otro". En lugar de percibir la inmigración como un fenómeno abstracto y aislado que provoca la inmediata reacción inmunitaria, elige lo personal y el contagio a través de los lazos del afecto. Welcome constituyó una intervención importante en el debate francés sobre la legislación, e incluso fue proyectada en la Asamblea Nacional el 18 de marzo de 2009 en un esfuerzo por convencer a los opositores de la reforma legislativa (Dahlberg, 2013: 50).

\subsection{Le Havre}

Una de las narraciones más antiguas de Franz Kafka, la que abre su primera antología de relatos Contemplación, editada en Leipzig en 1913, lleva por título "Niños en el camino vecinal". Se trata de un texto muy breve, que termina con estas palabras:

"Ya era la hora. Besé al que estaba a mi lado, a los tres más próximos solo les tendí la mano, y emprendí el camino de regreso; nadie me llamó. En la primera encrucijada, donde ya no podían verme, di media vuelta y, siguiendo unos senderos, corrí de nuevo hacia el bosque. Quería llegar a esa ciudad del sur de la que se decía en nuestra aldea:

- ¡No os imagináis qué gente hay allí! ¡Si es que no duermen!"

- ¿Y eso por qué?"

- Porque no se cansan."

- ¿Y eso por qué?"

- Porque son necios."

- ¿Y los necios no se cansan?"

- ¡Cómo podrían cansarse los necios?!" (Kafka, 2003: 10)

Una amiga, la dueña de una panadería de la pequeña calle en que reside en la ciudad normanda de El Havre, lee este fragmento de "Niños en el camino vecinal" a Arletty, la mujer del personaje principal de la película, a los pies de la cama de hospital en que ésta se halla postrada, con pocas esperanzas de recuperarse de un cáncer. Parece una extraña opción de lectura; sin embargo, casa bien con el tono abstracto, pero hiper-detallista, de esta fábula de Kaurismäki, pues en su narración Kafka recupera el ambiente campesino de la Bohemia rural en que nació su padre, deteniéndose en primera persona en el deseo de un niño de apartarse de la comunidad de juegos de sus amigos, con los que sale en tropel un atardecer, como una 
banda en apretada y enérgica carrera, a ver pasar los trenes de viajeros cerca del bosque. Quiere llegar a esa ciudad del sur habitada por locos frente a los labradores- que ni se cansan ni duermen - a diferencia de la gente del campo-.

El filme de Aki Kaurismäki tiene como protagonista a Marcel Marx, un hombre "tirado en el arroyo", como él mismo se define, que a una edad ya avanzada se emplea como limpiabotas en las calles y la estación de la ciudad portuaria de El Havre, en el departamento del Sena marítimo, tras haber abandonado la vida bohemia que llevó antaño en París. En una de sus solitarias pausas para almorzar en las escaleras de un muelle, se encuentra con Idrissa, un niño, casi ya un adolescente, que ha escapado de un contenedor que ha sido inmovilizado durante dos días en El Havre, mientras iba a ser transportado desde Gabón a Inglaterra. En su interior, se refugiaban varias familias gabonesas de "inmigrantes ilegales", que son detenidos e identificados mediante un despliegue, igualmente sensacionalista, de la policía y la prensa. A los cuerpos de estos desplazados - que provienen de un país perteneciente a la vieja federación del África Ecuatorial francesa, ocupan el lugar exacto de las mercancías y son tratados como cosas tanto por los servicios de seguridad como por los medios de comunicación-, el cineasta les dedica unos primeros planos individualizados, cargados de sobrio humanismo.

Marcel Marx, que deja a fiar casi todo lo que consume, alimenta al niño. Se gana su confianza. Éste lo sigue hasta su casa, donde es acogido. Arletty interpretada por la actriz finlandesa Kati Outinen, un icono de la filmografía de Kaurismäki desde Sombras en el paraíso (1986), la esposa que hacía las veces de alma fuerte y triste de ese hogar mantenido con los exiguos beneficios de la limpieza callejera de zapatos-, ha tenido que abandonar su feudo para ser ingresada. Alguien sale y alguien llega al hogar, a un mismo hogar. Dos personas muy distintas. Un joven gabonés en su viaje irregular hacia Londres, donde espera reencontrarse con su madre, trabajadora en una lavandería china - un apunte aparentemente banal, pero que da en la diana de los aspectos más desasosegantes de la globalización como gran trituradora de los procesos de descolonización-; y una sencilla ama de casa, ella misma una extranjera naturalizada francesa mediante años de residencia continuada, matrimonio - por más que su cónyuge sea una suerte de exilado interior como salido de La vida de Bohemia (1992) - y competencia lingüística. El hogar humilde de Marcel Marx en El Havre es la encrucijada de estos dos destinos inicialmente 
desahuciados: el del inmigrante y el de la enferma. Son dos cuerpos amenazados por dos formas distintas de inseguridad radical; dos cuerpos en tránsito.

Kaurismäki hace que Marx se desdoble en dos itinerarios diferenciados de la atención y el cuidado. El que parece priorizar es el cuidado al inmigrante, cuyos frentes son un campo de refugiados de Dunkerke y un centro de internamiento en Calais, en las fechas inmediatamente posteriores al desmantelamiento en 2009 de una "Bidón-Villa" levantada en su tristemente célebre "Jungla". El itinerario de atención a su mujer tiene como frente único el hospital, que él visita esporádicamente, pues la paciente desea mantenerlo lo más alejado posible de ella para evitarle sufrir, con lo que Arletty lleva al extremo más conmovedor su lógica del cuidado, como enferma protectora, que le evita a Marx la verdad de un diagnóstico que parece fatal. Le Havre no puede ser entendida sin el cruce de estos dos itinerarios del cuidado y sus relaciones con la verdad: la acogida del inmigrante moviliza en Marcel un proceso de búsqueda de la verdad (¿Cuál es su familia? ¿Dónde reside su madre en Reino Unido?), mientras que la atención a su esposa enferma de cáncer queda envuelta en la zona confortable de una mentira piadosa que le hace más llevadera su ausencia.

Ningún apellido carece de resonancia en esta fábula. El limpiabotas es Marx, el comisario es Monet, la esposa es Arletty, replicando el nombre artístico de la protagonista del filme Hotel du Nord de Marcel Carné, a la atmósfera física y moral de cuyos escenarios Kaurismäki homenajea en la distancia. Reconstruye el universo fílmico con absoluta fidelidad a su estilo, a la vez que hace una lectura muy personal del cine clásico francés que más admira: la gestualidad casi abstracta de Robert Bresson; los paisajes morales del realismo poético de Marcel Carné, y, desde luego, el polar francés, por medio del personaje del comisario criminalista, encargado de la operación dirigida a detener a Idrissa por orden expresa del prefecto de la ciudad, un papel de melancólico policía, de ética íntegra y pasado desintegrado, que guiña al universo de Jean Pierre Melville, mientras nos remite al corazón de la filmografía del propio Kaurismäki, especialmente a su I hired a contract killer / Contraté a un asesino a sueldo (1990).

Lo importante es el modo como hila sus historias, haciendo que dichas referencias cinematográficas transparenten a lo largo de todo su relato, sin estorbar en ningún momento al desarrollo cohesionado de su propuesta argumental y formal. Es como si dijera al espectador: está Vd. ante una 
película localizada en Francia que ama profundamente al cine francés $y$, desde ese amor quiere comenzar a hacer justicia a la representación de una realidad terrible, asumiendo un tono que es muy preciso con las circunstancias históricas narradas. La cadena que se escucha en casa de Marx es "Radio Realidad"; hay insertos de noticiarios de televisión que reportan puntualmente el desmantelamiento de la "Jungla de Calais", en una acción policial que el Ministro del Interior francés califica en sus declaraciones como "no dirigida contra los inmigrantes"; y no parece ninguna casualidad que la dirección de residencia de la madre de Idrissa en Londres, Whitechapel Road, 24, coincida exactamente con la de los jardines de la Iglesia de Santa María donde hoy se erige el memorial de Altab Ali, un trabajador bangladesí del sector textil asesinado en los setenta en un ataque racista instigado por el Frente Nacional. Pero al mismo tiempo, Le Havre tiene el sabor de una fábula, en cierto modo debido a sus opciones formales, como el tratamiento de la luz que bascula entre el realismo de los planos generales de exteriores y los golpes teatrales para enmarcar ad hoc las emociones de los personajes en los planos medios de interiores, como por ejemplo el reencuentro en un bar entre una vieja gloria local del Rock $\vartheta$ Roll, a la que se quiere enrolar en un concierto benéfico con que sufragar el pasaje clandestino de Idrissa a Londres, y la mujer con la que rompió tiempo atrás.

El tono de fábula afecta a capas más profundas del filme, sobre todo, a la recreación de la comunidad en que vive Marcel Marx. Esa calle diminuta en un barrio popular de El Havre, salpicada de tiendas, una panadería, una frutería, un bar, que - con excepción del caricaturesco soplón acechando tras las cortinas - hace las veces de toda una comunidad solidarizada con Idrissa. Se resisten a la autoridad, ocultándole información, burlando sus averiguaciones, tejiendo una red de asistencia al inmigrante liderada por Marcel, él mismo un acogido dentro de la vecindad. La comunidad de esa calle no ve en Idrissa una amenaza, más bien reconoce en él a un igual, como si fuera un barrio previamente deslindado de la sociedad de los fuertes y los iguales $y$, por eso mismo, más proclive a tratar como a un habitual a aquél que el resto de la opinión pública tilda de irregular. Se trata de un espacio marcado por el clima insólito de las zonas fronterizas, portuarias, de paso - con sus cafés "Le Moderne", sus parroquianos sin oficio y su tierra de nadie-, una comunidad que reúne de forma rara dos características que parecerían opuestas: la de desprender un genuino sabor local y la de ser un microcosmos completamente extraterritorial. El 
compañero de oficio de Marcel, es un joven vietnamita que ha tardado en obtener la naturalización y, víctima de sus paradojas administrativas, no duda en afirmar "Es difícil expulsar a un hombre anónimo, en el Mediterráneo hay más documentaciones que peces"; el propio Marcel reconoce que el de limpiabotas es el único oficio que respeta los preceptos del sermón de la montaña, una referencia llena de irónica retranca, pero de fondo muy serio, acerca de los avatares políticos y las contradicciones éticas padecidas por aquellas evangélicas bienaventuranzas dirigidas a los pacificadores, los hambrientos y los perseguidos.

Hay en Kaurismäki una ternura generalizada en el modo como pinta, no las situaciones, sino a aquellas almas silenciosas que las viven y encarnan. Ternura que, lejos de enmascarar la dureza política del asunto en cuestión, la saca a la luz de un modo doblemente revelador (algo que ocurre también en su más reciente aproximación al fenómeno de los refugiados sirios en la ya mencionada Toivon tuolla puolen). El abordaje que realiza de la conflictiva dialéctica contemporánea entre las tecnologías disciplinarias de inmunidad y las prácticas solidarias de comunidad es bastante menos naif de lo que aparenta. Frente a la priorización política de las normas de blindaje y autoprotección, Le Havre elige a la comunidad como centro de la narración. En realidad, las disciplinas inmunitarias - los campos de reclusión, los centros de internamiento, las baterías policiales apostadas frente a contenedores de mercancías humanas en esas "buffer zones" que son las terminales portuarias, los mass media extendiendo el miedo social y criminalizando con carácter preventivo al africano- son para Kaurismäki ficciones desmontables con el poder de un solo primer plano del rostro de Idrissa. Se puede afirmar que Le Havre demuestra cuál es el peso político y el potencial explicativo de la categoría de "inmunidad" en la Europa contemporánea ofreciendo al espectador un repertorio de prácticas que apuntan idealmente a la categoría contraria - pero complementaria-, la de una desbordante communitas.

La comunidad que acoge a Idrissa es una comunitas débil, "desobrada" (Nancy, 2001), excéntrica y, por eso mismo, naturalmente hospitalaria, sin caritativos buenismos ni hipocresías limosneras. Hecha de seres que se saben tan vulnerables como el inmigrante recién llegado. Marcel Marx es el eje de ese microcosmos, él mismo periférico, que es El Havre. Una comunidad que funciona realmente como tal, reconocible en sus lazos de vecindad, identificada con sus idiosincrasias locales, pero que no necesita arracimarse en torno a ningún santoral identitario, ni cree estar salvada por 
ninguna forma esencializada y vigilante de lo que es (y lo que no es) "nuestro". Como dice Blanchot siguiendo a Bataille:

“¿Por qué 'comunidad'? La respuesta está dada bastante claramente: 'En la base de cada ser, existe un principio de insuficiencia...' (principio de incompletud). (...) El ser, insuficiente, no busca asociarse a otro para formar una sustancia de integridad. La conciencia de la insuficiencia viene de su propio cuestionamiento, el cual tiene necesidad del otro o de algo distinto para ser efectuado. Solo, el ser se cierra, se duerme y se tranquiliza." (2002: 18).

No es una comunidad que vertebre sus vínculos y finja sus vulnerabilidades adosando al extraño un potencial catastrófico, para poder así rechazarlo al exacerbar mediante un gesto autodefensivo qué es propio e impropio, qué es legal e ilegal. Marcel Marx y su vecindario, en el que cobra una importancia determinante la presencia de mujeres independientes -que no solitarias-, forman una comunitas dentro de la cual resultaría antinatural calificar a nadie de "extraño". Ese es precisamente el secreto de su hospitalidad y de su fuerza como red solidaria con el perseguido.

Abundando en su tono de fábula, el final del filme opera una suerte de milagro duplicado. Idrissa logra zafarse del dispositivo policial, gracias a la intervención benefactora y cómplice del comisario, en un giro de guión como extraído del mejor Frank Capra; pero eso no quita para que Kaurismäki deje claro que su viaje como polizonte a Londres se paga al precio establecido por el mercado de movilidades clandestinas inducido por el sistema (3.000 euros recaudados con la caja del concierto de Rock $\&$ Roll). Arletty, por su parte, se cura de su enfermedad en una mejoría repentina e inesperada: "la enfermedad se ha ido completamente, volvamos a casa", dice de manera conmovedora a su marido al disponerse a salir del hospital. Volver a casa. Mientras Idrissa emprende un incierto viaje, que lo acerca a su madre y lo aleja quizás para siempre de su lugar de nacimiento, Arletty regresa a casa justo el día en que la ha desocupado el joven refugiado. Las dos categorías vertebradoras del espacio narrativo de la película, la inmigración y la enfermedad, vuelven a tocarse íntimamente en el tramo final de la película. Kaurismäki neutraliza, con su habitual comicidad silenciosa, la retórica social que convierte a la segunda en una metáfora de la primera.

La sanación de Arletty se produce cuando el joven gabonés sigue su viaje irregular y clandestino, abandonando el lugar provisional donde lo habian 
protegido. El vacío que dejó Arletty fue de algún modo ocupado por Idrissa. El hogar es ese vacío lleno de extraños y desplazados. En cierto sentido, la ley de la hospitalidad, encarnada por el limpiabotas Marcel, progresó al mismo tiempo que la enfermedad de su esposa. Lejos de pretender que ella solo puede regresar a casa cuando la enfermedad (Idrissa) ha desaparecido, el director defiende, con su habitual humanismo antisentimental, que, si hay todavía algo que merezca ser reconocido como un hogar al que volver, no se debe a que dicho espacio haya quedado en su ausencia exitosamente inmunizado frente al inmigrante, sino por haber sido compartido con él formando la comunidad, efímera y sin embargo resistente, de los igualmente vulnerables. Como expresión del nacimiento de ese vínculo imaginario, que subvierte todos los tics que tienden a unir el desarraigo con la enfermedad, Le Havre se cierra con la imagen de un cerezo en flor.

\section{CONCLUSIONES}

El cine contribuye, como los hacen todos los medios de comunicación, a forjar nuestras imágenes de la realidad, especialmente de aquellos aspectos de los que no tenemos un conocimiento directo, basado en experiencias subjetivas. Las dificultades que experimentan los inmigrantes y refugiados se transforman en los medios de comunicación en cifras y sucesos abstractos, sin acceso a las historias personales. Como apunta Ballesteros: "La forma en la que una comunidad se ve a si misma siempre es a través de los medios, y el cine desempeña un papel significativo al mostrar los límites entre los que están dentro y fuera de la sociedad" (2015: 12). Los discursos políticos tienden a enmarcar el debate sobre la inmigración en términos de protección e inmunización frente a una amenaza para las condiciones de vida y los estándares culturales de los ciudadanos europeos. Para evitar ese discurso del miedo y resentimiento hacia lo culturalmente diferente es precisa la articulación de narrativas alternativas que sitúan las relaciones humanas como su principal preocupación. Nussbaum sitúa claramente esta preocupación en el discurso humanista, en el que, como afirma la autora, se habla con un interlocutor a quien uno considera igualmente complejo y profundo" (2012: 6).

El cine se convierte en un instrumento privilegiado para desvelar la falacia de la pretensión inmunitaria que se sustenta en el miedo a no afrontar la subjetividad, a desvincularse de la obligación moral ante esas leyes 
absolutas que van más allá de los códigos penales específicos. Estas dos películas nos conectan con los encuentros afectivos que no se rechazan; son historias con el potencial para propagar el contagio del acercamiento al Otro. Desde estilos y perspectivas muy diferentes, Welcome expone el trágico desenlace con la muerte del joven Bilal mientras que Le Havre se decanta por una mirada esperanzadora enmarcada en la solidaridad con el Otro. Ambas películas revelan un esquema narrativo con marco político común: un inmigrante extraeuropeo, un gabonés o un iraqui-kurdo, recala en Francia en su itinerario clandestino hacia Reino Unido. El éxito de ese tránsito arriesgado e irregular acaba dependiendo, de manera inesperada, de la actitud que demuestre hacia él alguien que encarna en Francia la ley de la hospitalidad y el reconocimiento, en contra de las previsiones del aparato administrativo del estado, cuyos dispositivos inmunitarios se activan, dirigiéndose a arruinar el espacio común que han generado el refugiado y el nacional. Simon Calmat en Welcome y Marcel Marx en Le Havre encarnan esa ley desde sus propios presupuestos vitales. Ellos mismos quedan socialmente retratados, y emocionalmente transformados, al comprometerse con la suerte del otro. Una suerte sobre la que no pueden decidir totalmente, pues sus esfuerzos chocan paradójicamente con la realidad de la muerte que pretendian evitar, como en Welcome, o con la conciencia de que lo más que han logrado es perpetuar la clandestinidad del desplazamiento de aquel a quien han acogido, como en Le Havre.

Ambos filmes dejan en evidencia, desde estilos muy distintos pero complementarios, cuáles son las políticas con que Europa continental gestiona la lógica securitaria que prioriza las tecnologías de inmunidad para proteger formas aparentemente liberales, pero sistemáticamente discriminatorias, de comunidad. Son dos narraciones que, ya desde sus títulos, dejan en evidencia las inconsecuencias de la hospitalidad europea. La primera, nos ayuda a caer en la cuenta de ese genérico "Welcome" que funciona como un lugar común del lenguaje, pero no como un auténtico lugar de comunidad, es decir, nada más que una fraseología que hace las veces de un no-lugar del discurso. La otra, nos ofrece la idea de un espacio liminar, portuario, comunicativo y transfronterizo, El Havre, sobre el que los dispositivos policiales de autoprotección ejercen la soberanía de su presión inmovilizadora, haciendo diana en esas "terceras personas" (Esposito, 2009) a las que el compromiso de Simon y Marcel intentan sacar del régimen de impersonalidad propio de las mercancías. 


\section{Bibliografía}

Agamben, G. (1999). Homo sacer. El poder soberano y la nuda vida I. Valencia: Pre-Textos.

Appadurai, A. (1996). Modernity at Large. Minneapolis: University of Minnesota Press.

Bauman, Z. (2007). Miedo líquido. La sociedad contemporánea y sus temores. Buenos Aires: Paidós.

Balibar, E. (1997). Etat d'urgence démocratique. Le Monde (19 de febrero). Disponible en: http://www.bok.net/pajol/debat/presse/lemonde/balibar.html.

Ballesteros, I. (2015). Immigration Cinema in the New Europe. Bristol: Intellect.

Benveniste, E. (2007). Problemas de lingüistica general, I. México D.F.: Siglo XXI editores.

Blanchot, M. (2002). La comunidad inconfesable. Madrid: Arena Libros.

Dahlberg, L. (2013). Unwelcome Welcome: Being "at Home" in an Age of Global Migration. Law Text Culture, 17, 44-82.

Derrida, J. (2005). Canallas. Madrid: Trotta.

Derrida, J. (2006). La hospitalidad. Buenos Aires: Ediciones de la Flor.

Derrida, J. (2007). La diseminación. Madrid: Fundamentos.

Emmons, S. (1997). The Debre Bill: Immigration Legislation or a National "Front"? Indiana Journal of Global Legal Studies, 5(1), 356-366.

Esposito, R. (2005). Inmunitas. Protección y negación de la vida. Buenos Aires: Amorrortu.

Esposito, R. (2006a). Bios. Biopolitica y Filosofía. Buenos Aires/Madrid: Amorrortu editores.

Esposito, R. (2006b). Categorías de lo impolítico. Buenos Aires: Katz.

Esposito, R. (2009). Tercera persona. Política de la vida y filosofía de lo impersonal. Buenos Aires: Amorrortu.

Esposito, R. (2012). Inmunidad, Comunidad, Biopolítica. Las Torres de Lucca, 1, 101-114.

Foucault, M. (1989). Vigilar y castigar. El nacimiento de la prisión. Buenos Aires: Siglo XXI.

FRA-EU Agency for Fundamental Rights. (2014). Criminalisation of migrants in an irregular situation and of persons engaging with 
them.

Vienna:

FRA.

Disponible

en:

http://fra.europa.eu/sites/default/files/fra-2014-criminalisationof-migrants-0_en_0.pdf.

Kafka, F. (2003). Obras completas III. Narraciones y otros escritos. Barcelona: Galaxia Gutenberg/Círculo de Lectores.

Lykidis, A. (2009). Minority and Immigrant Representation in Recent European Cinema. Spectator, 29(1), 37-45.

Nancy, J. L. (2001). La comunidad desobrada. Madrid: Arena Libros.

Nancy, J. L. (2015). La comunidad descalificada. Madrid: Avarigani Editors.

Nussbaum, M. C. (2012). Not for Profit: Why Democracy Needs the Humanities. Princeton: Princeton University Press.

Parvulescu, A. (2014). The Traffic in Women's Work. East European Migration and the Making of Europe. Chicago: The University of Chicago Press.

Rancière, J. (2006). El odio a la democracia. Buenos Aires: Amorrortu.

Rancière, J. (2012). Las políticas de Pedro Costa. En Las distancias del cine. Buenos Aires: Manantial.

Smith, A. (2012). Crossing the linguistic threshold: Language, hospitality and linguistic exchange in Philippe Lioret's Welcome and Rachid Bouchareb's London River. Studies in French Cinema, 13(1), 75-90.

Spivak, G. Ch. (1999). A critique of postcolonial reason: Towards a history of the vanishing present. Cambridge: Harvard University Press.

Tauber, A. (1994). The immune self. Theory or Metaphor? New York and Cambridge: Cambridge University Press.

\section{FILMOGRAFÍA}

Fassbinder, R. W. (1974). Angs essen Seele auf. Alemania: New Yorker Films.

Kaurismäki, A. (1990). I hired a contract killer. Finlandia: Channel 4/Pandora Film.

Kaurismäki, A. (2011). Le Havre. Francia-Alemania-Finlandia: Sputnik/Pandora Film.

Kaurismäki, A. (2017). Toivon tuolla puolen. Finlandia-Alemania: Oy Bufo Ab/Sputnik/Pandora Film.

Lioret, P. (2009). Welcome. Francia: Nord-Ouest Films. 